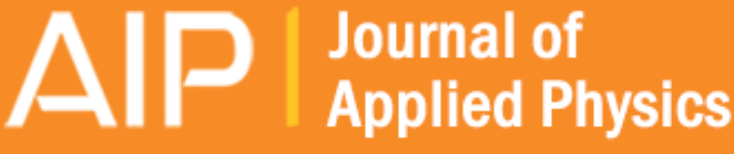

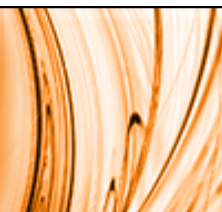

A comparative study of transport properties in polycrystalline and epitaxial chromium nitride films

X. F. Duan, W. B. Mi, Z. B. Guo, and H. L. Bai

Citation: Journal of Applied Physics 113, 023701 (2013); doi: 10.1063/1.4772682

View online: http://dx.doi.org/10.1063/1.4772682

View Table of Contents: http://scitation.aip.org/content/aip/journal/jap/113/2?ver=pdfcov

Published by the AIP Publishing

\section{Articles you may be interested in}

Electronic transport in heavily doped $\mathrm{Ag} / \mathrm{n}$-Si composite films

AlP Advances 3, 102111 (2013); 10.1063/1.4824854

The local structure, magnetic, and transport properties of Cr-doped In2O3 films

J. Appl. Phys. 113, 153901 (2013); 10.1063/1.4800828

Thickness dependent transport properties and percolative phase separation in polycrystalline manganite thin films

Appl. Phys. Lett. 93, 224104 (2008); 10.1063/1.3037202

Magnetotransport properties of polycrystalline and epitaxial chromium dioxide nanowires

J. Appl. Phys. 103, $07 D 710$ (2008); 10.1063/1.2836800

Optical, electronic, and transport properties of nanocrystalline titanium nitride thin films

J. Appl. Phys. 90, 4725 (2001); 10.1063/1.1403677

MIT LINCOLN

LABORATORY CAREERS

Discover the satisfaction of innovation and service

to the nation
- Space Control

- Air \& Missile Defense

- Communications Systems \& Cyber Security

- Intelligence, Surveillance and

Reconnaissance Systems

- Advanced
Electronics
- Tactical Systems
- Homeland
Protection
- Air Traffic Control

LINCOLN LABORATORY

MassachusetTs Institute of TeChNOLOgY

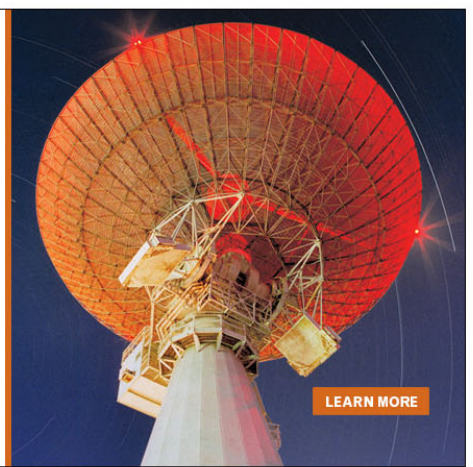




\title{
A comparative study of transport properties in polycrystalline and epitaxial chromium nitride films
}

\author{
X. F. Duan, ${ }^{1}$ W. B. Mi, ${ }^{1, a)}$ Z. B. Guo, ${ }^{2}$ and H. L. Bai ${ }^{1}$ \\ ${ }^{1}$ Tianjin Key Laboratory of Low Dimensional Materials Physics and Preparation Technology, \\ Institute of Advanced Materials Physics, Faculty of Science, Tianjin University, Tianjin 300072, China \\ ${ }^{2}$ Core Labs, King Abdullah University of Science and Technology (KAUST), Thuwal 23955-6900, \\ Saudi Arabia
}

(Received 19 October 2012; accepted 4 December 2012; published online 8 January 2013)

\begin{abstract}
Polycrystalline $\mathrm{CrN}_{x}$ films on $\mathrm{Si}(100)$ and glass substrates and epitaxial $\mathrm{CrN}_{x}$ films on $\mathrm{MgO}(100)$ substrates were fabricated by reactive sputtering with different nitrogen gas flow rates $\left(f_{\mathrm{N}_{2}}\right)$. With the increase of $f_{\mathrm{N}_{2}}$, a lattice phase transformation from metallic $\mathrm{Cr}_{2} \mathrm{~N}$ to semiconducting $\mathrm{CrN}$ appears in both polycrystalline and epitaxial $\mathrm{CrN}_{x}$ films. At $f_{\mathrm{N}_{2}}=100 \mathrm{sccm}$, the low-temperature conductance mechanism is dominated by both Mott and Efros-Shklovskii variable-range hopping in either polycrystalline or epitaxial $\mathrm{CrN}$ films. In all of the polycrystalline and epitaxial films, only the polycrystalline $\mathrm{CrN}_{x}$ films fabricated at $f_{\mathrm{N}_{2}}=30$ and $50 \mathrm{sccm}$ exhibit a discontinuity in $\rho(T)$ curves at $260-280 \mathrm{~K}$, indicating that both the $\mathrm{N}$-vacancy concentration and grain boundaries play important roles in the metal-insulator transition. (C) 2013 American Institute of Physics. [http://dx.doi.org/10.1063/1.4772682]
\end{abstract}

\section{INTRODUCTION}

$\mathrm{CrN}$ has a lot of important practical applications in hard and protective coatings due to its high hardness and good corrosion resistance. ${ }^{1,2}$ On the other hand, $\mathrm{CrN}$ has also attracted much attention as potential electronic or spintronic materials owing to its magnetic and electronic properties. ${ }^{3,4}$ Considerable experimental and theoretical work have demonstrated that $\mathrm{CrN}$ undergoes a magnetic and structural phase transition from a paramagnetic $\mathrm{NaCl}$ structure at room temperature to a low-temperature antiferromagnetic orthorhombic $P_{n m a}$ phase at Néel temperature of $273-286 \mathrm{~K}^{5-7}$

A variety of electrical transport properties in $\mathrm{CrN}$ have been observed, such as, a semiconducting behavior with $\mathrm{d} \rho / \mathrm{d} T<0,{ }^{8-11}$ a metallic behavior with $\mathrm{d} \rho / \mathrm{d} T>0,{ }^{12-14}$ and continuous and discontinuous $\rho(T)$ curves at $260-280 \mathrm{~K}^{.8-13,15}$ These differences in electrical transport properties have been attributed to the sensitivity of the transport properties to $\mathrm{N}$ stoichiometry. ${ }^{12,15}$ In addition, the discontinuity in $\rho(T)$ curves has usually been observed in $\mathrm{CrN}$ powders or polycrystalline $\mathrm{CrN}$ films, rather than in epitaxial films, suggesting that the epitaxial constraints could affect the transition. ${ }^{14,16}$ Therefore, it is necessary to carry out a comparative study of the electrical transport properties of polycrystalline and epitaxial $\mathrm{CrN}$ films with different $\mathrm{N}$ concentrations in order to clarify the conductance mechanism.

In this article, $\mathrm{CrN}_{x}$ films fabricated on $\mathrm{Si}(100)$, glass, and $\mathrm{MgO}(100)$ substrates at different nitrogen gas flow rates $\left(f_{\mathrm{N}_{2}}\right)$ by reactive sputtering have been investigated systematically. With the increase of $f_{\mathrm{N}_{2}}$, the dominant lattice phase transforms from metallic $\mathrm{Cr}_{2} \mathrm{~N}$ to semiconducting $\mathrm{CrN}$. The polycrystalline $\mathrm{CrN}_{x}$ films fabricated at $f_{\mathrm{N}_{2}}=30$ and $50 \mathrm{sccm}$ exhibit a discontinuity in $\rho(T)$ curves at $260-280 \mathrm{~K}$, indicating

\footnotetext{
${ }^{\text {a) }}$ Author to whom correspondence should be addressed. Electronic mail: miwenbo@tju.edu.cn.
}

a metal-insulator transition, while the transition is absent in all of $\mathrm{CrN}_{x}$ films on $\mathrm{MgO}(100)$ substrates.

\section{EXPERIMENTAL DETAILS}

$\mathrm{CrN}_{x}$ films were fabricated on $\mathrm{Si}(100), \mathrm{MgO}(100)$, and glass substrates by dc reactive facing-target sputtering from a pair of pure $\mathrm{Cr}$ targets $(4 \mathrm{~N})$ with base pressure better than $8.0 \times 10^{-6} \mathrm{~Pa}$. The sputtering pressure was kept at $1.0 \mathrm{~Pa}$ with a total $100-\mathrm{sccm}$ gas mixture of $\operatorname{Ar}(5 \mathrm{~N})$ and $\mathrm{N}_{2}(5 \mathrm{~N})$, in which, the $\mathrm{N}_{2}$ gas flow rates were set to $10,20,30,50,70$, and $100 \mathrm{sccm}$. The substrate temperature was kept at $550^{\circ} \mathrm{C}$ during film deposition. The film thickness was $\sim 140 \mathrm{~nm}$ determined by a Dektak 6M surface profiler. The structures of the films were characterized by x-ray diffraction (XRD) and transmission electron microscopy (TEM). The chemical states of each element were analyzed using x-ray photoelectron spectroscopy (XPS). The electrical transport properties were measured by a standard four-terminal method using a Quantum Design physical property measurement system (PPMS-9) in the temperature range of 2-305 K.

\section{RESULTS AND DISCUSSION}

Figure 1 shows the XRD patterns $(\theta-2 \theta)$ of $\mathrm{CrN}_{x}$ films on $\mathrm{Si}(100)$ substrates, revealing the evolution of various phases with different $f_{\mathrm{N}_{2}}$. Obviously, there is a transformation from $\mathrm{Cr}_{2} \mathrm{~N}+\mathrm{CrN} \rightarrow \mathrm{CrN}$ with the increase of $f_{\mathrm{N}_{2}}$. At $f_{\mathrm{N}_{2}}=10 \mathrm{sccm}$, three peaks from hexagonal $\mathrm{Cr}_{2} \mathrm{~N}(\overline{1} \overline{1} 1)$, (302), and $(\overline{2} \overline{2} 1)$ and a peak from the face-centered-cubic (fcc) $\mathrm{CrN}(111)$ can be observed. When $f_{\mathrm{N}_{2}}$ increases from 10 to 30 sccm, $\mathrm{CrN}(200)$ and (220) peaks appear and become stronger, accompanied by the weakening of the peaks from hexagonal $\mathrm{Cr}_{2} \mathrm{~N}$ phase. $\mathrm{CrN}$ phase becomes dominated at $f_{\mathrm{N}_{2}}=30 \mathrm{sccm}$. With further increasing the $f_{\mathrm{N}_{2}}(\geq 50 \mathrm{sccm})$, only the peaks from fcc $\mathrm{CrN}$ phase are present. Moreover, the (111) peak of $\mathrm{CrN}$ shifts to lower diffraction angle with 


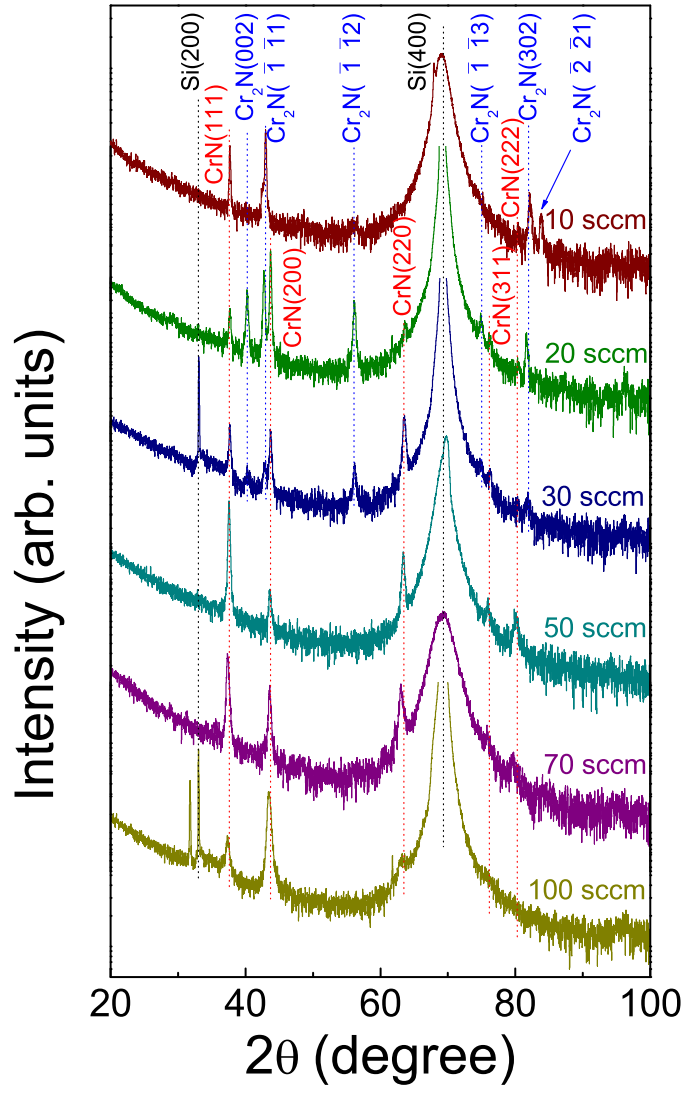

FIG. 1. XRD patterns of $\mathrm{CrN}_{x}$ films deposited on $\mathrm{Si}(100)$ substrates at different $f_{\mathrm{N}_{2}}$.

the increase of $f_{\mathrm{N}_{2}}$ because the increased nitrogen atoms make lattice constant become larger. ${ }^{15}$

Figure 2(a) gives the XRD patterns $(\theta-2 \theta)$ of $\mathrm{CrN}_{x}$ films on $\mathrm{MgO}(100)$ substrates. The diffraction peaks from $\mathrm{CrN}(h 00)$ or the overlap of $\mathrm{CrN}(h 00)$ and $\mathrm{MgO}(h 00)$ can be observed, indicating that the films grow along the (100) orientation. However, tilting $2 \theta$ scans need to be carried out
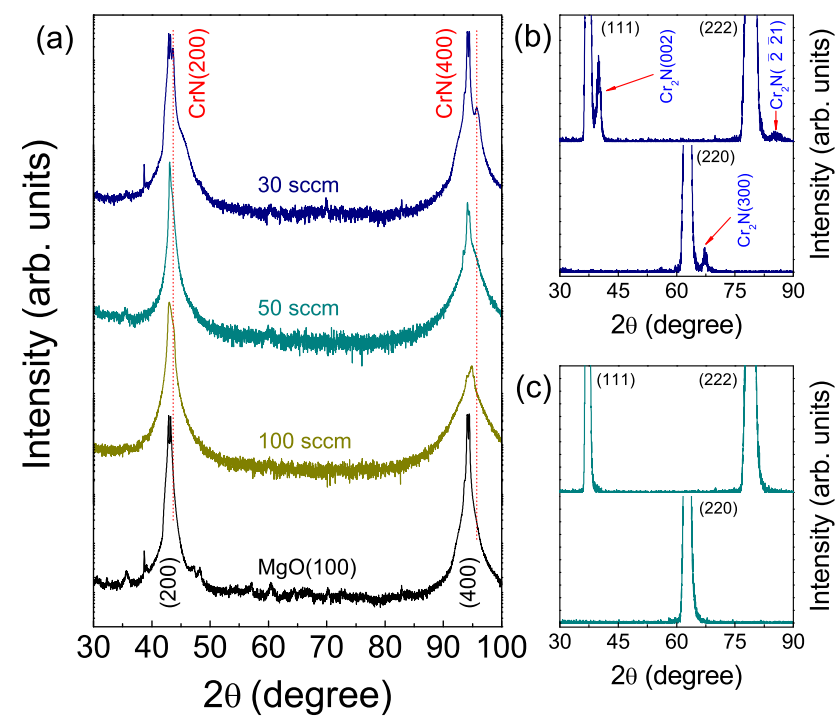

FIG. 2. (a) XRD patterns of $\mathrm{CrN}_{x}$ films deposited on $\mathrm{MgO}(100)$ substrates at different $f_{\mathrm{N}_{2}}$. (b) The tilting $2 \theta$ scans of $\mathrm{CrN}_{x}$ film fabricated at $f_{\mathrm{N}_{2}}=30$ sccm. (c) The tilting $2 \theta$ scans of $\mathrm{CrN}_{x}$ film fabricated at $f_{\mathrm{N}_{2}}=50 \mathrm{sccm}$. In (111) lattice, $\alpha=35.3^{\circ}, \beta=45^{\circ}$; in (110) lattice, $\alpha=45^{\circ}, \beta=0^{\circ}$. through rotating the sample by a certain degree to further clarify the structure, since the film fabricated at $f_{\mathrm{N}_{2}}=30$ $\mathrm{sccm}$ on $\mathrm{Si}(100)$ substrate consists of two phases and the orientation does not necessarily mean epitaxy. In tilting $2 \theta$ scans, (111) plane $\left(\alpha=35.3^{\circ}, \beta=45^{\circ}\right)$ and (110) plane $\left(\alpha=45^{\circ}, \beta=0^{\circ}\right)$ are chosen as the scanned planes. The tilting scans in Fig. 2(b) show that the $\mathrm{Cr}_{2} \mathrm{~N}(002),(\overline{2} \overline{2} 1)$, and (300) peaks are visible, revealing that two phases exist in the film fabricated at $f_{\mathrm{N}_{2}}=30 \mathrm{sccm}$ on $\mathrm{MgO}(100)$ substrate. For the tilting scans in Fig. 2(c), only (111), (222), and (220) diffraction peaks from the overlap of $\mathrm{CrN}$ and $\mathrm{MgO}$ are visible, suggesting that the film fabricated at $f_{\mathrm{N}_{2}}=50 \mathrm{sccm}$ on $\mathrm{MgO}(100)$ substrate is epitaxial, as discussed for epitaxial $\mathrm{Ti}_{1-x} \mathrm{Cr}_{x} \mathrm{~N}$ films. ${ }^{17}$ Accordingly, the films fabricated at $f_{\mathrm{N}_{2}}>50 \mathrm{sccm}$ on $\mathrm{MgO}(100)$ substrates are epitaxial.

In order to further investigate the microstructure of $\mathrm{CrN}_{x}$ films, the high-resolution TEM analysis was carried out at $\mathrm{CrN}_{x} /$ substrate interface fabricated at $f_{\mathrm{N}_{2}}=30 \mathrm{sccm}$, as shown in Fig. 3. The low-magnification image of $\mathrm{CrN}_{x} /$ glass interface is presented in Fig. 3(a), which shows a sharp interface and a film thickness of $\sim 140 \mathrm{~nm}$. Figure 3(b) gives the highresolution TEM image at $\mathrm{CrN}_{x} /$ glass interface, from which different oriented grains with blurred grain boundaries can be observed. The $d$ spacings indexed in Fig. 3(b) are from dominant $\mathrm{CrN}(200)$ and minor $\mathrm{Cr}_{2} \mathrm{~N}(102)$ planes. The corresponding selection area electron diffraction (SAED) in the inset of Fig. 3(b) displays rings, indicating a polycrystalline structure. Similarly, a film thickness of $\sim 140 \mathrm{~nm}$ can be observed in Fig. 3(c), though the contrast of the $\mathrm{CrN}_{x} / \mathrm{MgO}$ interface is blurred. The high-resolution TEM image in Fig. 3(d) shows the quasi-epitaxial growth of the film. The inset of Fig. 3(d) is the corresponding SAED, where the diffraction spots correspond to fcc structure. Actually, the spots are from the overlap of dominant fcc $\mathrm{CrN}$ and $\mathrm{Cr}_{2} \mathrm{~N}$, such as the overlap of $\mathrm{CrN}(220)$ and $\mathrm{Cr}_{2} \mathrm{~N}(300)$, which is consistent with the tilting $2 \theta$ scans in Fig. 2(b), confirming the existence of two phases in the film fabricated at $f_{\mathrm{N}_{2}}=30 \mathrm{sccm}$ on $\mathrm{MgO}(100)$ substrate.

For analyzing the valance states of the elements in the films fabricated at different $f_{\mathrm{N}_{2}}$, XPS measurements were performed to analyze the binding energy of $\mathrm{N}_{1 s}$ and $\mathrm{Cr}_{2 p}$, as shown in Fig. 4. In Fig. 4(a), the $\mathrm{N}_{1 s}$ peak positions of the films fabricated at $f_{\mathrm{N}_{2}}=30 \mathrm{sccm}$ are 396.8 and $397.0 \mathrm{eV}$, for $\mathrm{MgO}$ and $\mathrm{Si}$ substrate, respectively, while the $\mathrm{Cr} 2 p$ peak positions in Fig. 4(b) are identical for $\mathrm{MgO}$ and $\mathrm{Si}$ substrate. With the increase of $f_{\mathrm{N}_{2}}$ on Si substrate, there is a negative chemical shift of $\mathrm{N}_{1 s}$ peak from 397.0 to $396.8 \mathrm{eV}$, as shown in Fig. 4(a). Meanwhile, in Fig. 4(b), Cr $2 p_{3 / 2}$ peak shifts from 574.1 to $574.4 \mathrm{eV}$ and $\mathrm{Cr} 2 p_{1 / 2}$ peak shifts from 583.4 to $583.8 \mathrm{eV}$ with the increase of $f_{\mathrm{N}_{2}}$ on $\mathrm{Si}$ substrate. The simultaneous occurrence of negative chemical shift of $\mathrm{N}_{1 s}$ peak and positive chemical shift of $\mathrm{Cr} 2 p$ peak with the increase of $f_{\mathrm{N}_{2}}$ can be interpreted as increasing charge transfer from $\mathrm{Cr}$ to $\mathrm{N}$ with increasing nitrogen, ${ }^{18}$ indicating a decrease of $\mathrm{N}$-vacancy concentration with the increase of $f_{\mathrm{N}_{2}}$.

Figure 5(a) shows the temperature dependence of the normalized resistivity $\rho(T) / \rho(305 \mathrm{~K})$ of polycrystalline $\mathrm{CrN}_{x}$ films deposited on glass substrates under different $f_{\mathrm{N}_{2}}$. With the increase of $f_{\mathrm{N}_{2}}$, the conductance characteristic transforms from metallic to semiconducting. The films fabricated at 

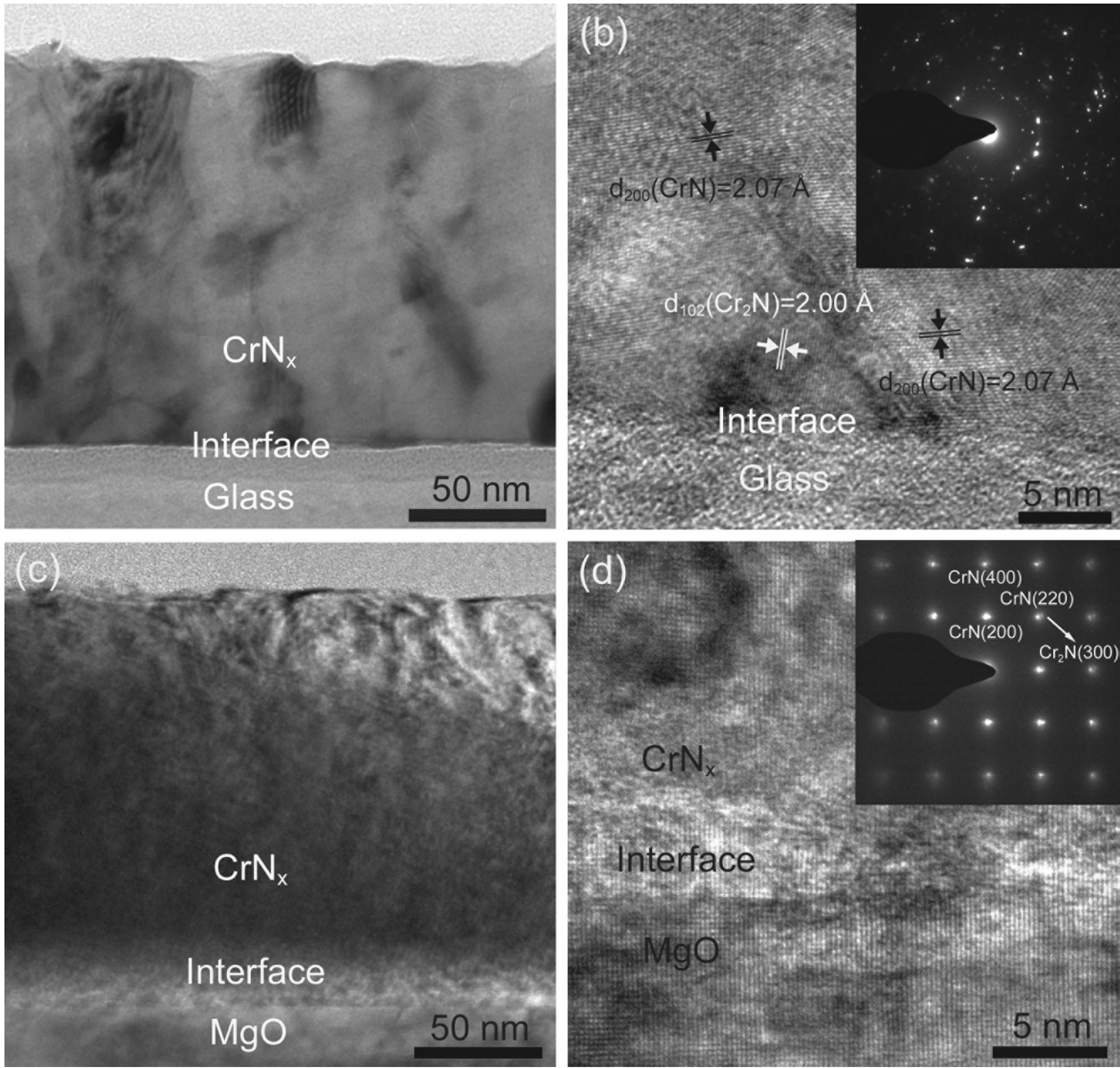

FIG. 3. (a) Cross-section TEM image and (b) cross-section high-resolution TEM image at the $\mathrm{CrN}_{x} /$ glass interface fabricated at $f_{\mathrm{N}_{2}}=30 \mathrm{sccm}$. (c) Crosssection TEM image and (d) crosssection high-resolution TEM image at the $\mathrm{CrN}_{x} / \mathrm{MgO}$ interface fabricated at $f_{\mathrm{N}_{2}}=30 \mathrm{sccm}$. The inset of (b) or (d) is the corresponding SAED.

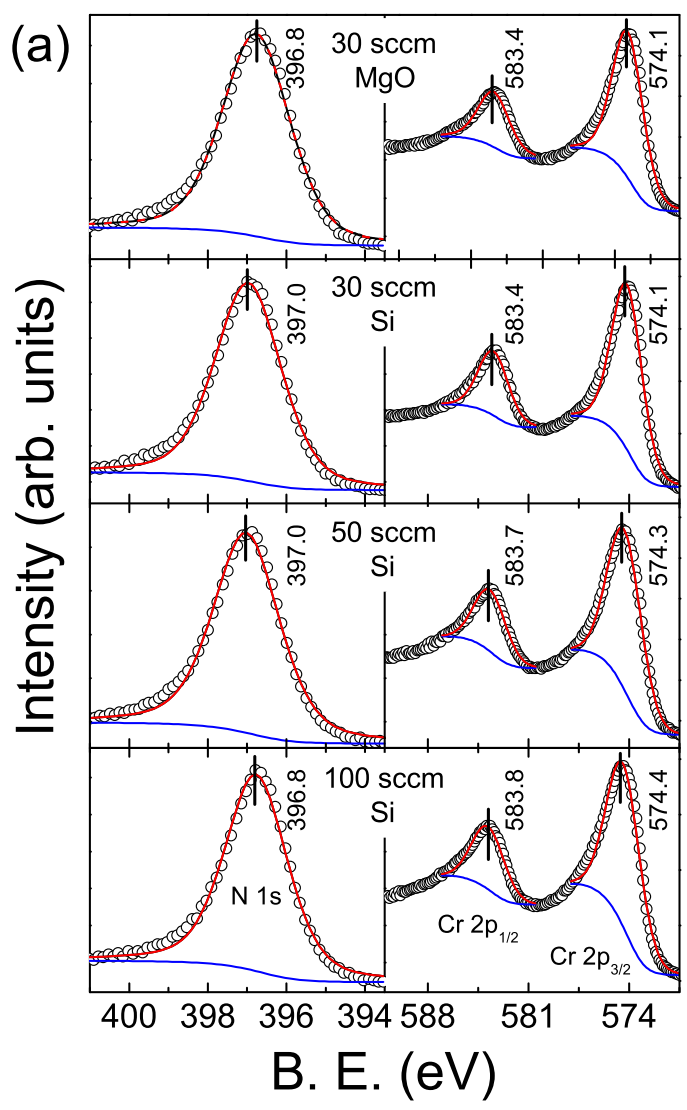

(b)

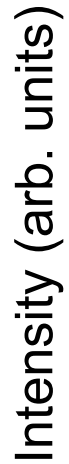

FIG. 4. (a) $\mathrm{N}_{1 \mathrm{~s}}$ and (b) $\mathrm{Cr}_{2 \mathrm{p}}$ XPS spectra of $\mathrm{CrN}_{x}$ films fabricated at different $f_{\mathrm{N}_{2}}$.

$f_{\mathrm{N}_{2}}=10$ and $20 \mathrm{sccm}$ are metallic, i.e., the resistivity decreases as temperature decreases. At $f_{\mathrm{N}_{2}}=30 \mathrm{sccm}$, the film exhibits a metal-insulator-like transition around $263 \mathrm{~K}$ [Fig. 5(b)]. When $f_{\mathrm{N}_{2}}$ reaches $50 \mathrm{sccm}$, the resistivity shows a steep decrease with decreasing temperature in the range of 260-280 K, and the resistivity increases with decreasing temperature for temperature less than $145 \mathrm{~K}$. The resistivity of the films fabricated at $f_{\mathrm{N}_{2}}=70$ and $100 \mathrm{sccm}$ increases with decreasing temperature, exhibiting semiconducting behavior [Fig. 5(c)]. As shown in the inset of Fig. 5(a), the room-temperature

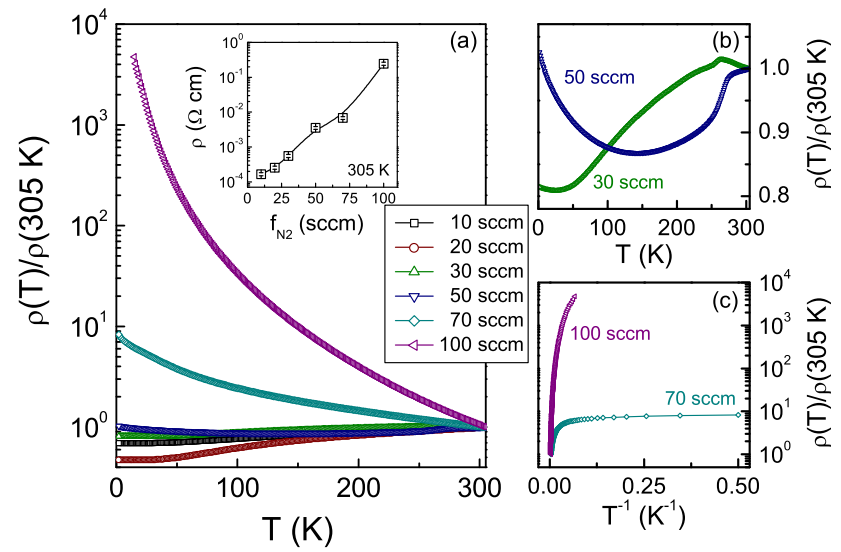

FIG. 5. (a) Normalized resistivity versus temperature of $\mathrm{CrN}_{x}$ films deposited on glass substrates. The top inset shows the dependence of $\rho(305 \mathrm{~K})$ on $f_{\mathrm{N}_{2}}$. (b) The magnified $\rho-T$ plot of the films fabricated at $f_{\mathrm{N}_{2}}=30$ and $50 \mathrm{sccm}$. (c) $\log \rho-T^{-1}$ curves for the films fabricated at $f_{\mathrm{N}_{2}}=70$ and $100 \mathrm{sccm}$. 
resistivity increases from $1.44 \times 10^{-4}$ to $0.25 \Omega \mathrm{cm}$ with the increase of $f_{\mathrm{N}_{2}}$, which is consistent with nitrogen-dependent resistivity of other transition metal nitrides such as $\mathrm{ZrN},{ }^{19,20}$ $\mathrm{TiN},{ }^{19-21}$ or $\mathrm{NbN},{ }^{22}$ and should be attributed to the increase of nitrogen composition. ${ }^{19-22}$ Figure 5(c) is a semilog plot of the normalized resistivity vs $T^{-1}$, for polycrystalline $\mathrm{CrN}$ films fabricated at $f_{\mathrm{N}_{2}}=70$ and $100 \mathrm{sccm}$. The plotted curves are nonlinear over the measured temperature range, indicating that the temperature dependence of resistivity cannot simply be explained by thermal activation.

Figure 6(a) shows the temperature dependence of the normalized resistivity $\rho(T) / \rho(305 \mathrm{~K})$ of $\mathrm{CrN}_{x}$ films on $\mathrm{MgO}(100)$ substrates fabricated at different $f_{\mathrm{N}_{2}}$. The films fabricated at $f_{\mathrm{N}_{2}} \leq 30 \mathrm{sccm}$ are metallic, while the films fabricated at $f_{\mathrm{N}_{2}} \geq 50 \mathrm{sccm}$ are semiconducting. It should be noted that the films fabricated at $f_{\mathrm{N}_{2}}=30$ and $50 \mathrm{sccm}$ show no anomaly on temperature dependence of resistivity, as shown in Fig. 6(b). The room-temperature resistivity of the films in the inset of Fig. 6(a) increases from $1.74 \times 10^{-4}$ to $1.24 \Omega \mathrm{cm}$, as $f_{\mathrm{N}_{2}}$ increases from 10 to $100 \mathrm{sccm}$. Similarly, $\rho(T)$ behaviors of the semiconducting epitaxial $\mathrm{CrN}$ films cannot also be described by thermally activated model, as shown in Fig. 6(c).

The variable-range hopping (VRH) resistivity of disordered systems was shown by Mott to behave as $\ln \rho \propto T^{-1 / 4},{ }^{23,24}$ while Efros and Shklovskii (ES) argued that Coulomb interactions create a gap that leads to $\ln \rho \propto$ $T^{-1 / 2}$ at low temperatures. ${ }^{25,26}$ Here, we use a universal scaling relation considering both Mott VRH and ES hopping, which has previously been reported for epitaxial $\mathrm{CrN}(001)$ films by Zhang et al. ${ }^{11}$ The expression first proposed by Aharony et al. ${ }^{27}$ is

$$
\ln \left(\rho / \rho_{0}\right)=A f\left(T / T_{x}\right),
$$

where the scaling factors $\rho_{0}, A$, and $T_{x}$ depend on individual material properties, but the function $f(x)$ is universal, given by ${ }^{27}$

$$
f(x)=\frac{1+\left[(1+x)^{1 / 2}-1\right] / x}{\left[(1+x)^{1 / 2}-1\right]^{1 / 2}} .
$$

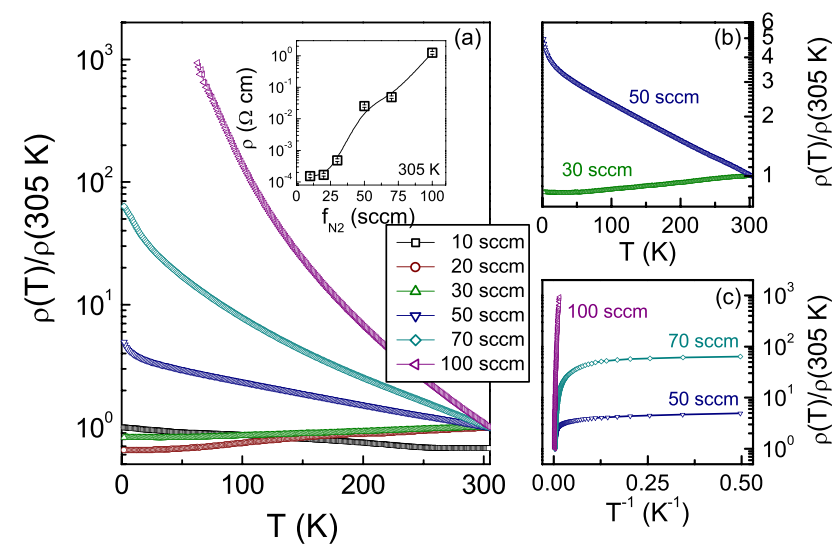

FIG. 6. (a) Normalized resistivity versus temperature of $\mathrm{CrN}_{x}$ films deposited on $\mathrm{MgO}(100)$ substrates. The top inset shows the dependence of $\rho(305 \mathrm{~K})$ on $f_{\mathrm{N}_{2}}$. (b) The magnified $\rho-T$ plot for the films fabricated at $f_{\mathrm{N}_{2}}=30$ and $50 \mathrm{sccm}$. (c) $\log \rho-T^{-1}$ curves for the films fabricated at $f_{\mathrm{N}_{2}}=50,70$, and $100 \mathrm{sccm}$.
To investigate whether our data can be described by the scaling function or not, the measured resistivity data are fitted using Eqs. (1) and (2) for the semiconducting CrN films. The resulting curves are plotted as red solid lines in Fig. 7. The scaling function could only well describe the temperaturedependent resistivity for polycrystalline $\mathrm{CrN}$ film fabricated at $f_{\mathrm{N}_{2}}=100 \mathrm{sccm}$ for $15 \mathrm{~K}<T<100 \mathrm{~K}$ in Fig. 7 (a) and the corresponding epitaxial film for $63 \mathrm{~K}<T<160 \mathrm{~K}$ in Fig. 7(b). These results indicate that the low-temperature electrical transport of $\mathrm{CrN}$ with the least $\mathrm{N}$ vacancy is dominated by both Mott VRH and ES VRH.

Finally, we focus on the discontinuity in $\rho(T)$ curves that has been reported to be associated with a structure transition of $\mathrm{CrN}$ from cubic to orthorhombic. At $f_{\mathrm{N}_{2}}=30$ and 50 sccm, polycrystalline $\mathrm{CrN}_{x}$ films show a transition of resistivity at $260-280 \mathrm{~K}$. Here, the $\mathrm{N}$-vacancy concentration may be just appropriate for the structure transition. The structure of cubic $\mathrm{CrN}$ without nitrogen vacancies is shown in Fig. $8(a)$, where the perfect lattice makes the transition difficultly appear, such as the $\mathrm{CrN}$ films fabricated at high $f_{\mathrm{N}_{2}}$. However, when there are nitrogen atoms lost, it is easy for the structure transition to happen near $T_{N}$ accompanying the relaxation of lattice strain, such as the films fabricated at low $f_{\mathrm{N}}$. Figures $8(\mathrm{~b})$ and $8(\mathrm{c})$ show the view of a $2 \times 2 \times 2 \mathrm{CrN}$ supercell with two nitrogen atoms lost along [110] direction, resulting in the lattice contraction along [110] direction and $\alpha<90^{\circ}$, as the temperature decreases and the lattice strain is relaxed. Thus, the structure transforms from cubic to orthorhombic.

With further increasing $f_{\mathrm{N}_{2}}(>50 \mathrm{sccm})$, N-vacancy concentration is small and the crowded nitrogen atoms go against the shear deformation of $\mathrm{CrN}$ grains into the orthorhombic structure. At lower $f_{\mathrm{N}_{2}}(10$ and $20 \mathrm{sccm}), \mathrm{N}$-vacancy concentration should be large, but the transition of resistivity cannot be observed because the dominant phase is metallic $\mathrm{Cr}_{2} \mathrm{~N}$ at lower $f_{\mathrm{N}_{2}}$, as shown in XRD results of Fig. 1, and the transition from $\mathrm{CrN}$ phase could be neglected, if any.

In contrast, for $f_{\mathrm{N}_{2}}=30$ and $50 \mathrm{sccm}, \mathrm{CrN}_{x}$ films on $\mathrm{MgO}$ substrates, do not show a transition of resistivity. As shown in Figs. 8(d) and 8(e), the presence and absence of phase transition may be explained as following: Polycrystalline $\mathrm{CrN}$ film

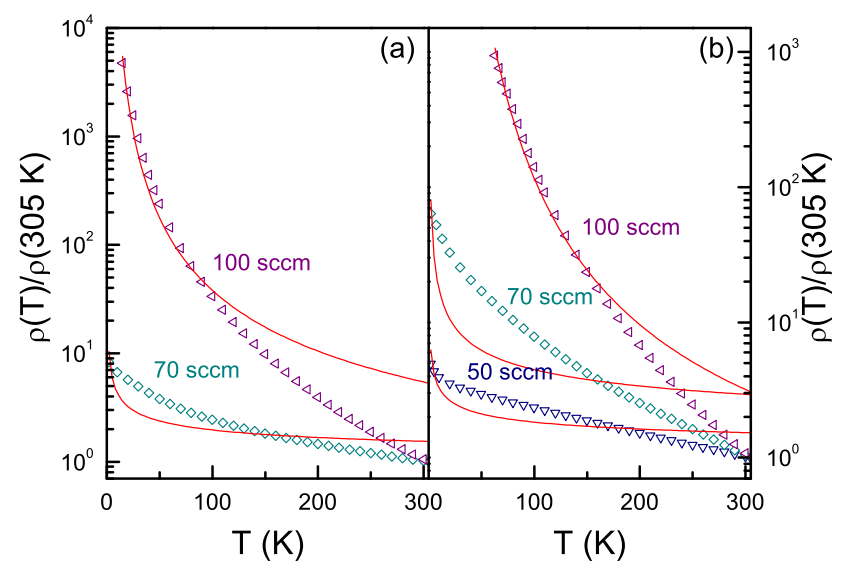

FIG. 7. Normalized resistivity versus temperature for (a) polycrystalline and (b) epitaxial CrN films. The lines are fitting data by Eqs. (1) and (2), and the symbols are the experimental data. 
(a)

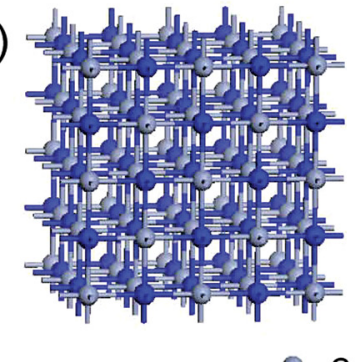

- $\mathrm{Cr}$

(d)

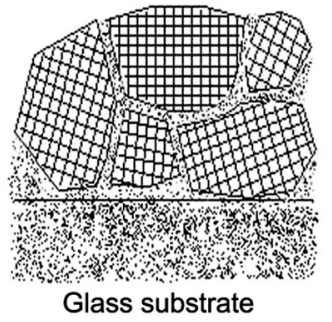

(b) Lossing $2 \mathrm{~N}$

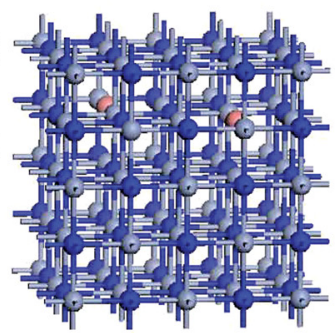

O Nv

(e)

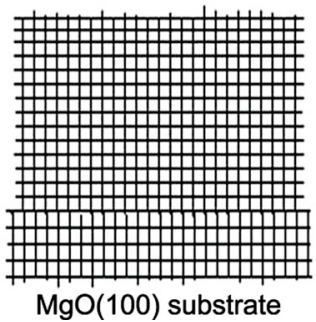

(c)

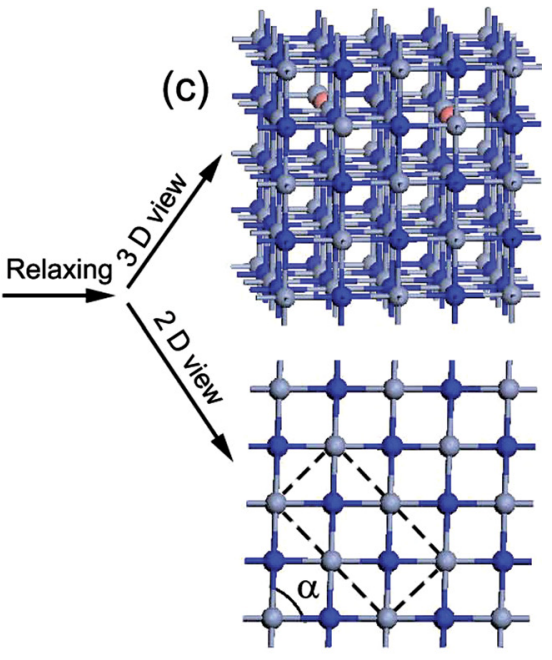

Relaxing

FIG. 8. Perspective view of (a) the cubic $\mathrm{CrN}$ cell and (b) the cubic $\mathrm{CrN}$ cell with two $\mathrm{N}$ atoms lost. (c) Perspective view and top view of the orthorhombic $\mathrm{CrN}$ cell with two $\mathrm{N}$ atoms lost. The red balls represent the nitrogen vacancies. Schematic diagram of (d) polycrystalline CrN film with several grains and (e) epitaxial CrN film.

should exhibit the phase transition since the transition is likely facilitated by underdense grain boundaries that allow grain slide and independent shear deformation for each grain. However, it is very hard for epitaxial CrN film to distort into orthorhombic structure, as two of its three crystal axes are fixed by the substrate.

\section{CONCLUSION}

Both polycrystalline and epitaxial $\mathrm{CrN}_{x}$ films fabricated by reactive sputtering show a phase change from $\mathrm{Cr}_{2} \mathrm{~N}+\mathrm{CrN}$ to $\mathrm{CrN}$ with increasing $f_{\mathrm{N}_{2}}$. Meanwhile, there is a transformation of conductance from metallic to semiconducting, and at $f_{\mathrm{N}_{2}}=100 \mathrm{sccm}$, the electrical transport at low temperatures is described by both Mott and ES VRH. The polycrystalline $\mathrm{CrN}_{x}$ films fabricated at $f_{\mathrm{N}_{2}}=30$ and 50 sccm exhibit a discontinuity in $\rho(T)$ curves at $260-280 \mathrm{~K}$, while the transition is absent in all of $\mathrm{CrN}_{x}$ films on $\mathrm{MgO}(100)$ substrates. The metal-insulator transition of $\mathrm{CrN}$ is strongly affected by $\mathrm{N}$-vacancy concentration as well as the substrate and associated grain boundaries.

\section{ACKNOWLEDGMENTS}

This work was supported by National Natural Science Foundation of China (51171126) and Key Project of the Natural Science Foundation of Tianjin City (12JCZDJC27100).

${ }^{1}$ U. Wiklund, M. Bromark, M. Larsson, P. Hedenqvist, and S. Hogmark, Surf. Coat. Technol. 91, 57 (1997).

${ }^{2}$ C. Nouveau, M. A. Djouadi, O. Banakh, R. Sanjinés, and F. Lévy, Thin Solid Films 398-399, 490 (2001).

${ }^{3}$ A. Ney, R. Rajaram, S. S. P. Parkin, T. Kammermeier, and S. Dhar, Appl. Phys. Lett. 89, 112504 (2006).

${ }^{4}$ P. A. Anderson, R. J. Kinsey, S. M. Durbin, M. Markwitz, J. Kennedy, A. Asadov, W. Gao, and R. J. Reeves, J. Appl. Phys. 98, 043903 (2005).
${ }^{5}$ L. M. Corliss, N. Elliott, and J. M. Hastings, Phys. Rev. 117, 929 (1960).

${ }^{6}$ R. M. Ibberson and R. Cywinski, Physica B 180-181, 329 (1992).

${ }^{7}$ A. Filippetti, W. E. Pickett, and B. M. Klein, Phys. Rev. B 59, 7043 (1999).

${ }^{8}$ P. S. Herle, M. S. Hegde, N. Y. Vasathacharya, S. Philip, M. V. R. Rao, and T. Sripathi, J. Solid State Chem. 134, 120 (1997).

${ }^{9}$ D. Gall, C.-S. Shin, R. T. Haasch, I. Petrov, and J. E. Greene, J. Appl. Phys. 91, 5882 (2002).

${ }^{10}$ C. X. Quintela, F. Rivadulla, and J. Rivas, Appl. Phys. Lett. 94, 152103 (2009).

${ }^{11}$ X. Y. Zhang, J. S. Chawla, B. M. Howe, and D. Gall, Phys. Rev. B 83, 165205 (2011).

${ }^{12}$ J. D. Browne, P. R. Liddell, R. Street, and T. Mills, Phys. Status Solidi 1, 715 (1970).

${ }^{13}$ C. Constantin, M. B. Haider, D. Ingram, and A. R. Smith, Appl. Phys. Lett. 85, 6371 (2004).

${ }^{14}$ K. Inumaru, K. Koyama, N. Imo-oka, and S. Yamanaka, Phys. Rev. B 75, 054416 (2007).

${ }^{15}$ Y. Tsuchiya, K. Kosuge, S. Yamaguchi, and N. Nakayama, Mater. Trans., JIM 37, 121 (1996).

${ }^{16}$ X. Y. Zhang, J. S. Chawla, R. P. Deng, and D. Gall, Phys. Rev. B 84, 073101 (2011).

${ }^{17}$ X. F. Duan, W. B. Mi, Z. B. Guo, and H. L. Bai, Acta Mater. 60, 3690 (2012).

${ }^{18}$ C. Emery, A. R. Chourasia, and P. Yasharb, J. Electron Spectrosc. Relat. Phenom. 104, 91 (1999).

${ }^{19}$ B. O. Johansson, H. T. G. Hentzell, J. M. E. Harper, and J. J. Coumo, J. Mater. Res. 1, 442 (1986).

${ }^{20}$ D. S. Yee, J. J. Coumo, M. A. Frisch, and D. P. Smith, J. Vac. Sci. Technol. A 4, 381 (1986).

${ }^{21}$ J. P. Schaffer, A. J. Perry, and J. Brunner, J. Vac. Sci. Technol. A 10, 193 (1992).

${ }^{22}$ D. D. Bacon, A. T. English, S. Nakahara, F. G. Peters, H. Schreiber, W. R. Sinclair, and R. B. van Dover, J. Appl. Phys. 54, 6509 (1983).

${ }^{23}$ N. F. Mott and E. A. Davis, Electronic Processes in Non-Crystalline Materials, 2nd ed. (Clarendon, Oxford, 1979).

${ }^{24}$ N. F. Mott, Metal-Insulator Transitions, 2nd ed. (Taylor \& Francis, Bristol, PA, 1990).

${ }^{25}$ A. L. Efros and B. I. Shklovskii, J. Phys. C: Solid State Phys. 8, L49 (1975).

${ }^{26}$ B. I. Shklovskii and A. L. Efros, Electronic Properties of Doped Semiconductor (Springer-Verlag, Berlin, 1984).

${ }^{27}$ A. Aharony, Y. Zhang, and M. P. Sarachik, Phys. Rev. Lett. 68, 3900 (1992). 